\title{
The Role of Telemedicine in Infectious Diseases
}

\author{
Authors: \\ Christina Pham, ${ }^{1}$ Melissa E. Badowski² \\ 1. College of Pharmacy, University of Illinois, Chicago, Illinois, USA \\ 2. Department of Pharmacy Practice, Section of Infectious Diseases \\ Pharmacotherapy, College of Pharmacy, University of Illinois, Chicago, Illinois, USA \\ *Correspondence to badowski@uic.edu \\ Disclosure: $\quad$ The authors have declared no conflicts of interest. \\ Received: \\ 18.09.18 \\ Accepted: \\ 26.03.19 \\ Keywords: \\ Antimicrobial stewardship, hepatitis, HIV, infectious diseases, pre-exposure \\ prophylaxis, telehealth, telemedicine. \\ Citation: \\ EMJ Innov. 2019 [Epub ahead of print]. DOI/10.33590/emjinnov/18-00085
}

\begin{abstract}
The use of telemedicine has been described for various medical conditions. Telemedicine can improve access to care, reduce geographic barriers, and optimise healthcare for patients. The role of telemedicine has been described in antimicrobial stewardship programmes for the management of both acute and chronic infectious diseases, including HIV and hepatitis. The goal of this review is to provide data on the implementation of synchronous telemedicine programmes to provide infectious disease management.
\end{abstract}

\section{INTRODUCTION}

The continuous advancement of technology provides opportunities to create, improve, and expand access to healthcare in varying populations using telehealth and telemedicine. The World Health Organization (WHO) defines telemedicine as "the delivery of health care services, where distance is a critical factor, by all health care professionals using information and communication technologies for the exchange of valid information for diagnosis, treatment, and prevention of disease and injuries, research and evaluation, and for the continuing education of healthcare providers, all in the interests of advancing the health of individuals and their communities." Although the terms 'telehealth' and 'telemedicine' are often used interchangeably, telehealth refers to 'a broad scope of remote healthcare services', while telemedicine refers specifically to the

provision of remote clinical services. ${ }^{2}$ Numerous benefits have been realised through the practice of telemedicine because of wider availability and acceptance by both patients and medical practitioners in this growing clinical practice. Clinical and educational benefits have led to increased availability and affordability of equipment, changes to Medicare and Medicaid reimbursement, and increased billing parity laws. In addition, the potential for cost savings to not only the patient, but also healthcare systems, has led to additional interest in this mode of providing healthcare.

The use of telemedicine in infectious diseases is an expanding clinical practice with the goal of optimising clinical outcomes and improving access to care. It provides a link to healthcare that patients with acute infectious diseases and chronic infections, such as HIV and hepatitis $C$ virus (HCV), and those who live in rural or isolated populations, may not have access 
to otherwise. In addition, telehealth may provide improvement to access in cases like pre-exposure prophylaxis (PrEP) to assist in preventing HIV. Despite the expanding practice of telemedicine in infectious diseases, the Infectious Diseases Society of America (IDSA) is the only infectious diseases organisation that has a formal position statement on the use of telehealth and telemedicine. The purpose of this position statement is to educate members of IDSA on the use of telehealth and telemedicine technologies, as well as promote IDSA's position on the use of such technologies, specifically in the field of infectious diseases. ${ }^{2}$ This literature review will evaluate and focus on the growing number of telemedicine programmes for use in the evaluation and treatment of infectious diseases.

\section{SOURCES AND SELECTION OF CRITERIA}

Articles pertaining to the role of telemedicine in infectious diseases between $1^{\text {st }}$ January 2015 and $13^{\text {th }}$ March 2019 were identified through EMBASE, PubMed/Medline, Cumulative Index to Nursing and Allied Health Literature (CINAHL), and Google Scholar databases. Additional literature was identified through bibliography review from articles obtained through search databases. "Telemedicine", "telehealth", "infectious diseases", "HIV", "hepatitis C", "PrEP", and "antimicrobial stewardship" were key terms included in the literature search. While international articles were searched through EMBASE, CINAHL, and Google Scholar, only English language articles were included.
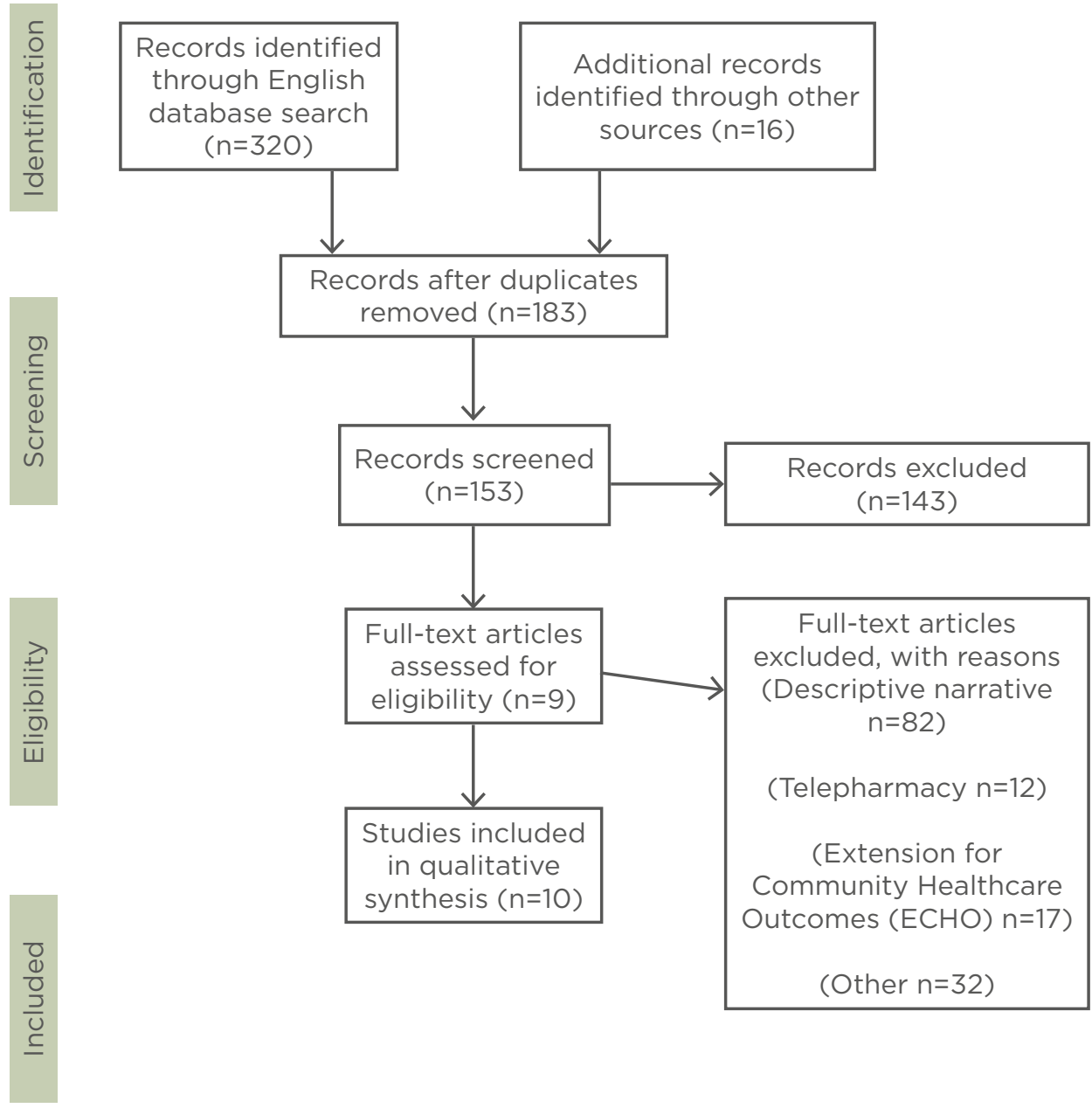

Figure 1: PRISMA flow diagram of the selection process of the studied literature. 
Because a previous review on the use of telemedicine in the specialty of infectious diseases was previously published in 2014, ${ }^{3}$ the authors limited their search to studies after this period to avoid any redundancy in the literature. For the purpose of this review, articles involving infectious diseases programmes with synchronous telemedicine (two-way video conferencing) and programme evaluation (outcome data and/or patient satisfaction) were included. Articles pertaining to telepharmacy, descriptive site narratives, and Extension for Community Healthcare Outcomes (ECHO) were excluded to focus on synchronous telemedicine programmes with documented clinical outcomes (Figure 1).

\section{RESULTS}

\section{Antimicrobial Stewardship}

Telemedicine in antimicrobial stewardship provides additional opportunities to address concerns of growing antimicrobial resistance. In southern Brazil, a 220-bed hospital designed a web-based platform to facilitate immediate post-prescription review of clinical data and provide feedback to physicians from remote infectious diseases specialists. ${ }^{4}$ After data collection on its use, the programme increased the rate of appropriate antimicrobial prescribing from $51.4 \%$ to $81.4 \%$ (Table 1 ). ${ }^{3}$ In Italy, a highly specialised paediatric cardiac hospital developed and implemented a remote infectious diseases consulting stewardship program via telemedicine. ${ }^{5}$ This remote stewardship programme consisted of bi-weekly virtual meetings of all inpatient clinical cases facilitated through real-time online discussions. A high-definition camera, microphones, realtime sharing of files, desktop sharing, and radiographic images were available to the medical team. The hospital performed a 'before and after' study comparing the time before the programme implementation and 1 year after. They found a trend in the reduction of nosocomial infections, overall antibiotic cost, and average antibiotic prescriptions used per admission (Table 1). ${ }^{5}$

\section{Acute Infectious Diseases}

In rural or isolated populations, infectious diseases can often be mismanaged when there is a lack of access to health services and care by medical personnel whose expertise lies in infectious diseases. In addition, the IDSA supports the use of telemedicine to provide timely access to those in need of infectious disease care. ${ }^{2}$

A study evaluating the effect of telemedicine (three times per week) versus on-site infectious disease consultation (standard of care [SOC]) in the management of Staphylococcus aureus bacteraemia [SAB]) was performed. This retrospective cohort analysis of adult patients included 163 patients in the telemedicine intervention compared to 583 in the SOC group, and found no difference in SAB bundle adherence, 30-day mortality, 30-day SABrelated readmission, persistent bacteraemia, or time-to-culture clearance between groups. ${ }^{6}$

The 32 First Nations communities in the Sioux Lookout region in Ontario, Canada, is afflicted by a high incidence and rate of infectious diseases, such as tuberculosis, acute rheumatic fever, and skin and soft tissue infections, compared to the rest of Canada. ${ }^{7}$ In 2014, a telemedicinebased consultation programme was developed between the Sioux Lookout Meno Ya Win Health Centre, the Sioux Lookout regional hospital, and the Division of Infectious Diseases at The Ottawa Hospital in Ontario, Canada. ${ }^{7}$ During the data collection period between July 2014 and July 2015, patient satisfaction surveys for the provision of telemedicine were conducted after each patient's initial video-consultation, with an overall patient satisfaction rate of 98\% (Table 1). ${ }^{7}$

In North Carolina, USA, the Division of Infectious Diseases at the Carolinas Healthcare System (now Atrium Health) developed a virtual face-toface inpatient infectious diseases consultation service for an outlying community hospital. ${ }^{8}$ Infectious diseases consultations, most commonly regarding bacteraemia, skin and soft tissue infection, osteomyelitis, prosthetic joint infection, and urinary tract infections, were provided for 312 patients in the 175-bed hospital from January 2015 to December 2015; during that period, there were only 13 patients who required transfer to a tertiary facility, with a 20\% 30-day readmission rate for all patients. ${ }^{8}$ 
Table 1

\begin{tabular}{|c|c|c|c|}
\hline Type & Reference & Study design & Results/outcomes \\
\hline $\begin{array}{l}\text { Antimicrobial } \\
\text { stewardship }\end{array}$ & Dos Santos et al., ${ }^{4} 2018$ & $\begin{array}{l}\text { - Quasi-experimental study in } \\
\text { a } 220 \text {-bed hospital in southern } \\
\text { Brazil. } \\
\text { - Web-based platform designed } \\
\text { to facilitate review of clinical data } \\
\text { and } \\
\text { provision of feedback } \\
\text { to physicians. }\end{array}$ & $\begin{array}{l}\text { - Appropriate antimicrobial prescribing } \\
\text { increased from } 51.4 \% \text { at baseline to } 81.4 \% \text {. } \\
\text { - Significant reduction in consumption of } \\
\text { fluoroquinolones (level change, } \beta=-0.80 ; p< \\
\text { 0.01; trend change, } \beta=-0.01 ; p=0.98 \text { ), first- } \\
\text { generation, cephalosporins (level change, } \beta=- \\
0.91 ; p<0.01 \text {; trend change, } \beta=+0.01 ; p=0.96 \text { ), } \\
\text { vancomycin (level change, } \beta=-0.47 ; p=0.04 ; \\
\text { trend change, } \beta=+0.17 ; p=0.66 \text { ), and polymyxins } \\
\text { (level change, } \beta=-0.15 ; p=0.56 \text {; trend change, } \\
\beta=-1.75 ; p<0.01 \text { ). } \\
\text { - Significant reduction in the rate of } \\
\text { carbapenem-resistant } A \text { cinetobacter spp. } \\
\text { isolation }(\text { level change, } \beta=+0.66 ; p=0.01 ; \text { trend } \\
\text { change, } \beta=-1.26 ; p<0.01 \text { ). }\end{array}$ \\
\hline $\begin{array}{l}\text { Antimicrobial } \\
\text { stewardship }\end{array}$ & Ceradini et al., 52017 & $\begin{array}{l}\text {-A 'before - after' study compared } \\
\text { the period immediately before } \\
\text { programme } \\
\text { initiation and } 1 \text { year after. } \\
\text {-Evaluated the impact of a remote } \\
\text { stewardship. } \\
\text { programme based on a) } \\
\text { appropriateness of antibiotic } \\
\text { prescribing, b) } \\
\text { incidence of multi-resistant } \\
\text { infection, and c) cost. }\end{array}$ & $\begin{array}{l}\text { - A trend in the reduction of nosocomial } \\
\text { infections ( } 9.5 \text { vs } 6.5 \text { per 1,000 person-days). } \\
\text { - A reduction in the overall antibiotic cost } \\
\text { ( } 25,000 \text { vs } 15,000 \text { EUR) and in the average } \\
\text { antibiotics packages/prescriptions used per } \\
\text { admission ( } 9.0 \text { vs } 6.7 \text { packages/prescriptions). } \\
\text { - A significant reduction in multi-drug resistant } \\
\text { isolation rate was observed (104 vs } 79 \text { per 1,000 } \\
\text { person-days, } p=0.01) \text {. }\end{array}$ \\
\hline $\begin{array}{l}\text { Acute/general } \\
\text { infectious } \\
\text { diseases }\end{array}$ & Isip et al., ${ }^{6} 2018$ & $\begin{array}{l}\text {-Retrospective, cohort analysis } \\
\text { compared inpatient adults } \\
\text { with Staphylococcus aureus } \\
\text { bacteremia (SAB) between } \\
\text { September } 2016 \text { and December } \\
2017 \text { to compare outcomes of ID } \\
\text { consultation received through } \\
\text { telemedicine or } \\
\text { on-site consultation on clinical } \\
\text { outcomes. }\end{array}$ & $\begin{array}{l}\text { - No difference was observed between groups } \\
\text { on the basis of adherence to SAB bundle, } \\
\text { mortality, readmission, or culture clearance. }\end{array}$ \\
\hline $\begin{array}{l}\text { Acute/general } \\
\text { infectious } \\
\text { diseases }\end{array}$ & Mashru et al., 2017 & $\begin{array}{l}\text { - Patient satisfaction surveys } \\
\text { were conducted following each } \\
\text { patient's } \\
\text { initial consultation. Each survey } \\
\text { evaluated the patient experience } \\
\text { related } \\
\text { to technical components and } \\
\text { physician-patient interaction } \\
\text { through } \\
\text { telemedicine over a } \\
1 \text { year period. }\end{array}$ & $\begin{array}{l}\text { - Overall patient satisfaction was } 98 \% \text { in the } \\
\text { nine questions asked of each patient. } \\
\text { 1) Patient understood the nurse's explanation of } \\
\text { how their session would run. } \\
\text { 2) Help was available if problems were to arise. } \\
\text { 3) Able to hear specialist comfortably. } \\
\text { 4) Satisfied with picture quality of specialist. } \\
\text { 5) Privacy was respected. } \\
\text { 6) Would use telemedicine again. } \\
\text { 7) Would recommend to family/friends. } \\
\text { 8) Overall satisfied with appointment. } \\
\text { 9) Number of team members was } \\
\text { not overwhelming. }\end{array}$ \\
\hline
\end{tabular}


Table 1 continued.

\begin{tabular}{|c|c|c|c|}
\hline Type & Reference & Study design & Results/outcomes \\
\hline $\begin{array}{l}\text { Acute/general } \\
\text { infectious } \\
\text { diseases }\end{array}$ & McCurdy et al.,, 2016 & $\begin{array}{l}\text { - Retrospective review of a virtual } \\
\text { on-call ID consulation service } \\
\text { evaluated diagnosis, transfer, 30- } \\
\text { day readmission, } \\
\text { and ambulatory care } \\
\text { follow-up. }\end{array}$ & $\begin{array}{l}\text { - Remote ID consultation performed for } 312 \\
\text { patients. } \\
\text { - } 13 \text { patients required transfer to a tertiary } \\
\text { facility with the majority transferred for surgical } \\
\text { evaluation. } \\
\text { - } 91 \text { patients ( } 29 \% \text { ) were prescribed } \\
\text { outpatient parenteral antibiotic therapy } \\
\text { written by ID physician. } \\
\text { - } 30 \text {-day readmission rate for all patients was } \\
20 \% \text { with only } 14 \text { ( } 4 \% \text { ) patients readmitted for } \\
\text { ID-related complications. }\end{array}$ \\
\hline Hepatitis C & Cooper et al.., 2017 & $\begin{array}{l}\text { - A cohort database analysis was } \\
\text { performed on patients following } \\
\text { at the } \\
\text { Ottawa Hospital and Regional } \\
\text { Viral Hepatitis Program between } \\
\text { January } \\
2012 \text { and August } 2016 \\
\text { - Compared patient } \\
\text { characteristics, fibrosis work-up, } \\
\text { and antiviral } \\
\text { treatment outcomes in TM } \\
\text { (n=157) and } \\
\text { non-TM ( } n=1,130) \text { patients. }\end{array}$ & $\begin{array}{l}\text { - SVR rates with interferon-free, DAA regimens } \\
\text { were } 94.7 \% \text { and } 94.8 \% \text { in TM and non-TM } \\
\text { groups }(p=0.99) \text {, respectively. }\end{array}$ \\
\hline Hepatitis C & McPherson et al..," 2018 & $\begin{array}{l}\text { - To review results of the } \\
\text { implementation of universal offer } \\
\text { of blood borne virus testing in } \\
\text { Durham Prison and the impact of } \\
\text { the introduction of Telemedicine } \\
\text { HCV treatment clinics in } \\
\text { Northumberland Prison. }\end{array}$ & $\begin{array}{l}\text { - } 57 \text { ( } 71 \% \text { ) of prisoners commenced anti-HCV } \\
\text { treatment while receiving consultant-led } \\
\text { TM clinic visits compared to the preceding year } \\
\text { prior to implementation where only six patients } \\
\text { received HCV treatment. } \\
\text { - Overall, patient satisfaction using TM in the } \\
\text { prison setting was very high ( } 80 \% \text { good or } \\
\text { excellent). } \\
\text { - Additionally, this intervention was cost } \\
\text { effective and reduced the cost of prisoner } \\
\text { movement ( } £ 500 / \text { hospital visit). }\end{array}$ \\
\hline Hepatitis C & Lepage et al.,12 2018 & $\begin{array}{l}\text { - The Ottawa Hospital Viral } \\
\text { Hepatitis Program was evaluated } \\
\text { for patients entering HCV } \\
\text { care from January 1, } 2012 \text { until } \\
\text { December 31, } 2016 \text {. }\end{array}$ & $\begin{array}{l}\text { - Per protocol SVR for TM, OPC, and MD } \\
\text { patients with DAA- based treatments were } \\
\text { 100\% (26/26), 93\% (440/472), and 94\% } \\
\text { (44/47), respectively. } \\
\text { - Interferon - DAA treatment regimens, SVR } \\
\text { rates were 100\% (1/1) for TM, 92\% ( } 76 / 83) \text { for } \\
\text { OPC, and 100\% (3/3) for MD patients. } \\
\text { - Interferon-based treatments, SVR rates for } \\
\text { OPC and MD patients were 64\% (134/211) and } \\
80 \%(4 / 5) \text {, respectively. } \\
\text { - SVR rates, when controlled for treatment } \\
\text { allocation, were similar by care-delivery } \\
\text { method ( } p=0.93) \text {. }\end{array}$ \\
\hline HIV & Baguley et al., ${ }^{14} 2018$ & $\begin{array}{l}\text { - Attend Anywhere consultations } \\
\text { as part of medical care for people } \\
\text { living with HIV and in remote } \\
\text { areas where care is received. } \\
\text { - Patients visit their primary } \\
\text { provider for blood tests at a time } \\
\text { convenient for them. Afterwards, } \\
\text { a teleconsultation from home } \\
\text { using the Attend Anywhere app } \\
\text { can be performed. }\end{array}$ & $\begin{array}{l}\text { - Despite small enrollment, the service is } \\
\text { popular with patients who have used it. } \\
\text { - Authors noted that the majority of people will } \\
\text { be required to attend follow-up appointments in } \\
\text { person due to their symptoms or testing } \\
\text { requirements. }\end{array}$ \\
\hline
\end{tabular}




\begin{tabular}{|c|c|c|c|}
\hline Type & Reference & Study design & Results/outcomes \\
\hline PrEP & Refugio et al.,15 2019 & $\begin{array}{l}\text { - PrEPTECH is a pilot study that } \\
\text { enrolled } 25 \text { HIV-negative young } \\
\text { men } \\
\text { who have sex with men to } \\
\text { participate in TM visits and } \\
\text { receive cost-free PrEP delivered } \\
\text { to their home. } \\
\text { - Patients had to participate in } \\
\text { two laboratory visits at baseline } \\
\text { and } 90 \text { days post PrEP initiation. }\end{array}$ & $\begin{array}{l}\text { - No HIV infections detected during the } \\
\text { intervention period. } \\
\text { - Rates of sexually transmitted infections were } \\
20 \% \text { at baseline and } 19 \% \text { at } 90 \text { days. }\end{array}$ \\
\hline
\end{tabular}

DAA: direct-acting antiviral; HCV: hepatitis C virus; ID: infectious diseases; MD: mixed deliver; OPC: outpatient clinic; PrEP: pre-exposure prophylaxis; SAB: Staphylococcus aureus bacteraemia; SVR: sustained virologic response; TM: telemedicine.

To assist with the increasing infectious diseases burden, telemedicine programmes have the ability to connect patients in those populations with multidisciplinary infectious diseases specialised teams who can provide them with the necessary treatment and care to optimise clinical outcomes.

\section{Hepatitis}

Telemedicine programmes can play a vital role in addressing WHO's objectives of increasing access to care and promoting health services geared toward the treatment of hepatitis. According to the WHO, hepatitis B and C currently affect approximately 325 million people worldwide. ${ }^{9}$ The organisation aims to achieve global elimination of viral hepatitis by the year 2030 by increasing hepatitis prevention, testing, treatment, and care services, promoting universal health coverage of hepatitis services, and improving partnerships and funding in the fight against hepatitis. ${ }^{9}$

In Canada, data analysis was performed on patients followed at The Ottawa Hospital and Regional Viral Hepatitis Program from January 2012 to August 2016 comparing sustained virologic response (SVR) between patients in the multidisciplinary telemedicine programme and patients in a nontelemedicine programme seen at the Ottawa Hospital Viral Hepatitis Outpatient Clinic. ${ }^{10}$ This programme was created as part of an effort to engage and retain rural and remote populations that lacked access to HCV subspecialty care. Patients in the telemedicine group had an SVR rate of $94.7 \%$ and patients in the nontelemedicine group had an SVR rate of $94.8 \%$ (Table 1). ${ }^{10}$

In prisons in the North-East of England, UK, a universal offer of blood borne virus testing was offered and prison telemedicine clinics to increase HCV treatment rates." In one of the prisons, 80 patients were seen in the telemedicine clinic between August 2015 and October 2017."1 Prior to the introduction of the telemedicine clinic, only six patients received access to treatment for $\mathrm{HCV}$. Postimplementation of the HCV programme, anti$\mathrm{HCV}$ treatment was increased to 57 of the 80 patients seen in clinic." The prisoners in the telemedicine clinic reported a high satisfaction rate ( $80 \%$ good or excellent) and a reduced cost of prisoner movement (estimated $£ 500$ per hospital visit) with the programme."

The Ottawa Hospital Viral Hepatitis Program evaluated patients in $\mathrm{HCV}$ care from January 2012 to December 2016 and compared SVR between patients enrolled in telemedicine clinic, outpatient clinic, and mixed-delivery. ${ }^{12}$ The study found that telemedicine-delivered, direct-acting antiviral-treated patients achieved higher SVR outcomes: the per protocol SVR rates for telemedicine, outpatient, and mixeddelivery with direct acting antiviral treatments were 100\% (26/26), 93\% (440/472), and 94\% (44/47), respectively. ${ }^{12}$ 
With increased access to HCV treatment made possible with telemedicine and the availability of direct acting antivirals, along with their safety and efficacy, viral eradication of HCV by 2030 may turn into a reality.

\section{Human Immunodeficiency Virus}

While advancements in HIV medications have provided patients with options to prevent and treat HIV, it remains a serious health issue for many worldwide. The Centers for Disease Control and Prevention (CDC) estimated that in 2016 there were 36.7 million people living with HIV, only 19.5 million people of which were receiving treatment. ${ }^{13}$ Rural and isolated populations may lack access to HIV specialised care and treatment. The National Health Services (NHS) Grampian in Scotland provides HIV care to patients from the Orkney and Shetland islands by flying patients into Aberdeen for lab tests and consultations. ${ }^{14}$ In 2017, the NHS Scotland implemented the 'Attend Anywhere' application, a platform in which patients would receive secure video consultation from home after completing blood work at their own convenience at a general medical practice on their island. ${ }^{14}$ By implementing the programme, the NHS provided patients living with HIV in remote areas with a wider range of health services and care.

Telemedicine programmes provide and promote access to specialised HIV care for patients who might not have otherwise received treatment. With the advent of safer and simpler antiretroviral regimens and the expansion of telemedicine to manage this chronic disease, reduced transmission of HIV may be possible because of improved virologic suppression.

\section{Pre-exposure Prophylaxis}

Numerous barriers to PrEP access and continued use have been reported in patients receiving the treatment. For instance, stigma, cost, and adherence to the medication, as well as medical appointments, are often cited as hurdles for patients to access treatment. A study in 25 young men who have sex with men aged 18-25 performed in San Francisco, California, USA, evaluated the use of cost-free PrEP through telehealth services. This telemedicine model provided home delivery of PrEP at no cost to the participant, as well as sexually transmitted infection kit testing. Two physical lab visits were required at baseline and 90-days after initiation of PrEP for HIV and associated tests. Participants were followed longitudinally over 180 days. Twenty-one participants completed the study with no cases of HIV detected, yet rates of sexually transmitted infection remained the same. At least $75 \%$ of participants reported the intervention to be confidential, fast, convenient, and easy to use. Less than $15 \%$ of participants reported PrEP stigma. ${ }^{15}$

\section{DISCUSSION}

Increased access to testing, health services and care, cost-effectiveness, and decrease of inappropriate antimicrobial prescriptions are some of the many benefits that have come from the aforementioned telemedicine programmes. While there has been an upward trend of telemedicine programs since the early 2000s, the growth of these programmes has somewhat plateaued. Infectious diseases, acute or chronic, often require treatment and care from providers who have the training and expertise; however, access to these providers is limited for many populations. Programmes, such as the Ottawa Hospital Viral Hepatitis telemedicine clinic that resulted in patients with high SVR rates and the Brazilian Hospital remote consultation that increased appropriate antimicrobial prescriptions, demonstrate that telemedicine can provide some of the same benefits as face-to-face consultation while reducing geographic barriers to care and improving healthcare access and treatment.

While the programmes highlight the benefits of telemedicine use, there are some limitations in how these programmes were studied. Some of the programmes used patient satisfaction questionnaires instead of clinical assessments or laboratory measures to evaluate their outcomes, which may not be reliable measurement on the efficacy of telemedicine clinics. Another limitation was the settings of the studies. Most of the programmes were developed and implemented in developed countries and may not reflect generalisability for use in areas that do not have access to the technology necessary to apply telemedicine. Laboratory testing for safety and efficacy of treatment or intervention may be another limitation of telemedicine because patients still have to go to a testing site to have 
labs drawn. Many of these programmes had small sample sizes and warrant further studies with larger sample sizes to better determine the costeffectiveness of these programmes as well as demonstrate the clinical benefits of telemedicine. Furthermore, the available data is rather heterogeneous, with little ability to compare across studies.

\section{CONCLUSION}

As the usage of and advancements in technology continue to grow, telemedicine is a viable option to provide health services, treatment for acute and chronic infectious diseases, and prevention of HIV. This review demonstrates the value of implementing telemedicine for the use of infectious diseases and the need for continuous development of such programmes to expand access to healthcare.

\section{References}

1. World Health Organization (WHO). Telemedicine: Opportunities and developments in Member States: Report on the second global survey on eHealth. 2010. Available at: http:// www.who.int/goe/publications/ goe telemedicine_2010.pdf. Last accessed: 17 September 2018.

2. Siddiqui $\mathrm{J}$ et al. Infectious Diseases Society of America position statement on telehealth and telemedicine as applied to the practice of infectious diseases. Clin Infect Dis. 2017;64(3)237-42.

3. Parmar $\mathrm{P}$ et al. Use of telemedicine technologies in the management of infectious diseases: A review. Clin Infect Dis. 2015;60(7):1084-94.

4. Dos Santos R et al. Antimicrobial stewardship through telemedicine and its impact on multi-drug resistance. J Telemed Telecare. 2018:1357633X18767702. [Epub ahead of print].

5. Ceradini $\mathrm{J}$ et al. Telemedicine as an effective intervention to improve antibiotic appropriateness prescription and to reduce costs in pediatrics. Ital J Pediatr. 2017:43(1):105.
6. Isip J et al. 1868. Successful use of telemedicine vs. on-site infectious diseases consultation after implementation of a systemwide antimicrobial stewardship-led staphylococcus aureus bacteremia care bundle. Open Forum Infect Dis. 2018;5:S534.

7. Mashru J et al. Management of infectious diseases in remote northwestern Ontario with telemedicine videoconference consultations. J Telemed Telecare. 2017;23(1):83-7.

8. McCurdy $L$ et al. The successful use of telemedicine with virtual face-to-face evaluation for inpatient infectious disease consultation. Abstract 1682. Open Forum Infectious Diseases ID Week, 26-30 October, 2016.

9. World Health Organization (WHO). World hepatitis day. 2018. Available at: http://www.who.int/whocampaigns/world-hepatitis-day/2018. Last accessed 17 March 2019.

10. Cooper $\mathrm{CL}$ et al. Direct-acting antiviral therapy outcomes in Canadian chronic hepatitis $C$ telemedicine patients. Ann Hepatol. 2017:16(6):874-80
11. McPherson S et al. PTU-116 increased diagnosis and treatment of $\mathrm{HCV}$ in prison by universal testing and use of telemedicine. Gut. 2018;67:A248-9.

12. Lepage CDJ et al. Telemedicine outcomes in the hepatitis $\mathrm{C}$ direct acting antiviral era. Abstract P1-066. 16th International Symposium on Vira Hepatitis and Liver Diseases, 14-17 June, 2018.

13. Centers for Disease Control and Prevention (CDC). HIV/AIDS: Basic statistics. 2018. Available at: https:// www.cdc.gov/hiv/basics/statistics. html. Last accessed 17 March 2019.

14. Baguley S, Brawley D. A new model for remote HIV care: Experience in the use of the Attend Anywhere video consultation platform. Abstract P222. 4th Joint Conference of the British HIV Association, BHIVA with the British Association for Sexual Health and HIV, 17-20 April, 2018.

15. Refugio ON et al. Brief report: PREPTECH: A telehealth-based initiation program for HIV preexposure prophylaxis in young men of color who have sex with men. A pilot study of feasibility. J Acquir Immune Defic Syndr. 2019:80(1):40-5. 